\title{
Prevention of infectious complications after laparoscopic appendectomy for complicated acute appendicitis - the role of routine abdominal drainage
}

\author{
Pierre Allemann • Herve Probst • Nicolas Demartines • \\ Markus Schäfer
}

Received: 10 May 2010 / Accepted: 12 August 2010/Published online: 10 September 2010

(C) Springer-Verlag 2010

\begin{abstract}
Purpose Complicated acute appendicitis is still associated with an increased morbidity. If laparoscopy has been accepted as a valid approach, some questions remain concerning intra-abdominal abscess formation. Routine prophylactic drainage of the abdomen has been proposed. However, this practice remains a matter of debate, poorly validated in the literature. With the present study, we investigated the impact of drainage in laparoscopic appendectomy for complicated appendicitis.

Method This is a case match study of consecutive patients operated on by laparoscopy in a single institution. One hundred and thirty patients operated for complicated appendicitis (local peritonitis without perforation, with perforation, or with periappendicular abscess) with prophylactic intraperitoneal drainage were matched one by one to 130 patients operated without drainage. Uncomplicated appendicitis and generalized peritonitis were excluded. Primary endpoint was surgical complications and secondary endpoints were transit recovery time and length of hospital stay.
\end{abstract}

Author contributions

- Study conception and design: Allemann Pierre, Probst Hervé, Demartines Nicolas

- Acquisition of data: Allemann Pierre

- Analysis and interpretation of data: Allemann Pierre, Probst Hervé, Schäfer Markus

- Drafting of manuscript: Allemann Pierre, Probst Hervé, Schäfer

Markus

- Critical revision of manuscript: Demartines Nicolas, Schäfer Markus

P. Allemann $\cdot$ H. Probst $\cdot$ N. Demartines $(\bowtie) \cdot$ M. Schäfer Department of Visceral Surgery, Centre Hospitalier Universitaire Vaudois, University Hospital,

Rue du Bugnon 46,

1011 Lausanne, Switzerland

e-mail: demartines@chuv.ch
Results Patients without drain had significantly less overall complications $(7.7 \%$ vs. $18.5 \%, p=0.01)$. Moreover, the absence of drainage was of significant benefit for transit recovery time ( 2.5 vs. 3.5 days, $p=0.0068)$ and length of hospital stay ( 4.2 vs. 7.3 days, $p<0.0001$ ).

Conclusion No benefits were observed for prophylactic drainage of the abdominal cavity during emergency laparoscopic treatment of complicated appendicitis. For this reason, this practice may be abandoned.

Keywords Laparoscopy · Appendectomy · Complicated appendicitis $\cdot$ Drainage $\cdot$ Complication

\section{Introduction}

Acute appendicitis represents the most common acute abdominal disease that requires emergency surgery for its definitive cure. Whereas uncomplicated appendicitis can safely be treated with a low complication rate, complicated appendicitis with perforation, abscess formation, and generalized peritonitis is still associated with an increased postoperative morbidity $[1,2]$. Open appendectomy has been the standard treatment for more than a century, but since the advent of minimal invasive surgery during the late 1980s, laparoscopy has been adopted by many surgeons and institutions as novel approach to remove the inflamed appendix [3-14]. The main advantages of laparoscopic appendectomy are the decreased wound infection rate and the shorter hospital stay $[4,7,8,14-16]$. However, there is some concern on intra-abdominal abscess formation, which may be more frequent because of spillage within the abdominal cavity of infectious contents, promoted by the carbon dioxide pneumoperitoneum [14].

Routine prophylactic drainage of the abdominal cavity after laparoscopic appendectomy is a common practice in 
order to prevent abscess formation, particularly in case of perforation and pre-existing periappendicular abscess. Nevertheless, the role of this practice remains an ongoing matter of debate [17-25]. Routine drainage of the abdominal cavity after various types of surgical interventions has been a robust dogma in abdominal surgery for many decades. It has been assumed that drainage of fluid collections, anastomosis at risk, and "dead spaces," particularly in infected areas, would prevent postoperative intra-abdominal infectious complications by evacuating infected fluids, and early heralding anastomotic leakage and bleeding, respectively. For this reason, drains have been routinely used after nearly every kind of surgical intervention. Type and number of drains, as well as the timing of its removal have been largely dependent on the surgeon's preference, personal experience, and institutional guidelines. Nevertheless, the policy of routine abdominal drainage is increasingly questioned. For liver as well as for colorectal surgery, it has been shown that drains are not always beneficial, but may even harm [26]. As a consequence, there is an evolving trend towards a no-drain policy in many surgical fields during the last years.

The aim of the current study was to assess the impact of routine abdominal drainage after laparoscopic appendectomy for complicated appendicitis on the incidence of postoperative surgical complications.

\section{Method}

\section{Patients}

Three hundred and twenty consecutive patients, identified from our prospective databases, underwent laparoscopic appendectomy for complicated acute appendicitis from the 1st of November 2003 to the 30th of June 2007 at the Department of Visceral Surgery, University Hospital of Lausanne, Switzerland. Complicated acute appendicitis was defined on the intraoperative status, as acute inflammation of the appendix with a reddish aspect of the surrounding peritoneum (localized peritonitis), perforation of the appendix, presence of pus, or fibrin membranes around the appendix or frank periappendicular abscess. In order to further stratify the severity of the inflammation, all cases were also classified, based on histological findings (phlegmonous appendicitis, perforated appendicitis and periappendicular abscess). Patients with simple acute appendicitis (i.e., no peritoneal reaction), generalized peritonitis, preoperatively known immunodeficiencies, aged $<16$ years and incomplete dataset were not included in further analysis. This study received a complete approval of the ethical committee of our institution.
Endpoints

The primary endpoint was the event of surgical complication, defined as: intra-abdominal abscess with positive bacterial culture, intra-abdominal fluid collection without available culture, abdominal wall infection, cutaneousenteric fistula, abdominal wall hematoma, and late transit (no flatus and nausea/vomiting at more than three postoperative days). They were graded according to the severity, using a validated therapy-orientated complication score [27], and were reported as number of complications (i.e. more than one complication per patient possible, as stated in the description of the score).

There were two secondary endpoints: the transit recovery time, defined by the presence of flatus with complete tolerance of full realimentation, in days and the cumulative length of hospital stay, in days.

Case match and statistical analysis

After internal review of all the cases treated during 1 year, we hypothesized that this complication rate (primary endpoint) could be decreased by $50 \%$ without the routine use of drains from $15 \%$ to $7.5 \%$. For an alpha of $5 \%$ and a power of $80 \%$, a minimum sample size of 236 patients (118 pairs) was calculated.

Finally, 260 patients (155 male and 105 female patients, median age of 34 years old, range 16-75 years) were included. One hundred and thirty laparoscopic appendectomies without postoperative drainage were matched one by one by handwork, scrutinizing consecutively by an independent reviewer with 130 laparoscopic appendectomies with routine postoperative drainage. Matching criteria were age $(<50,50-70,>70$ years), ASA score (I-II, III-IV), BMI $\left(<30,>30 \mathrm{~kg} / \mathrm{m}^{2}\right)$, and pathological finding (local peritonitis without perforation, local peritonitis with perforation, and perforation with periappendicular abscess). The selection process is presented in Fig. 1 as a flowchart and the patient's characteristics are presented in Table 1.

Outcomes between the drain and no-drain group were analyzed by using McNemar and Wilcoxon test, as appropriate. Univariate analysis of the influence of the type of the drain was performed using ANOVA test. We performed all analyses using SPSS 15.0 for Windows (SPSS Inc, Chicago, IL).

Surgical management

A standardized operative technique was used for all patients. A 5-day antibiotic treatment was started at anesthesia induction, according to the institutional guidelines edited by our infectious disease department (amoxicillin/clavunalanic acid or ciprofloxacin and metronidazol 
Fig. 1 Selection process diagram

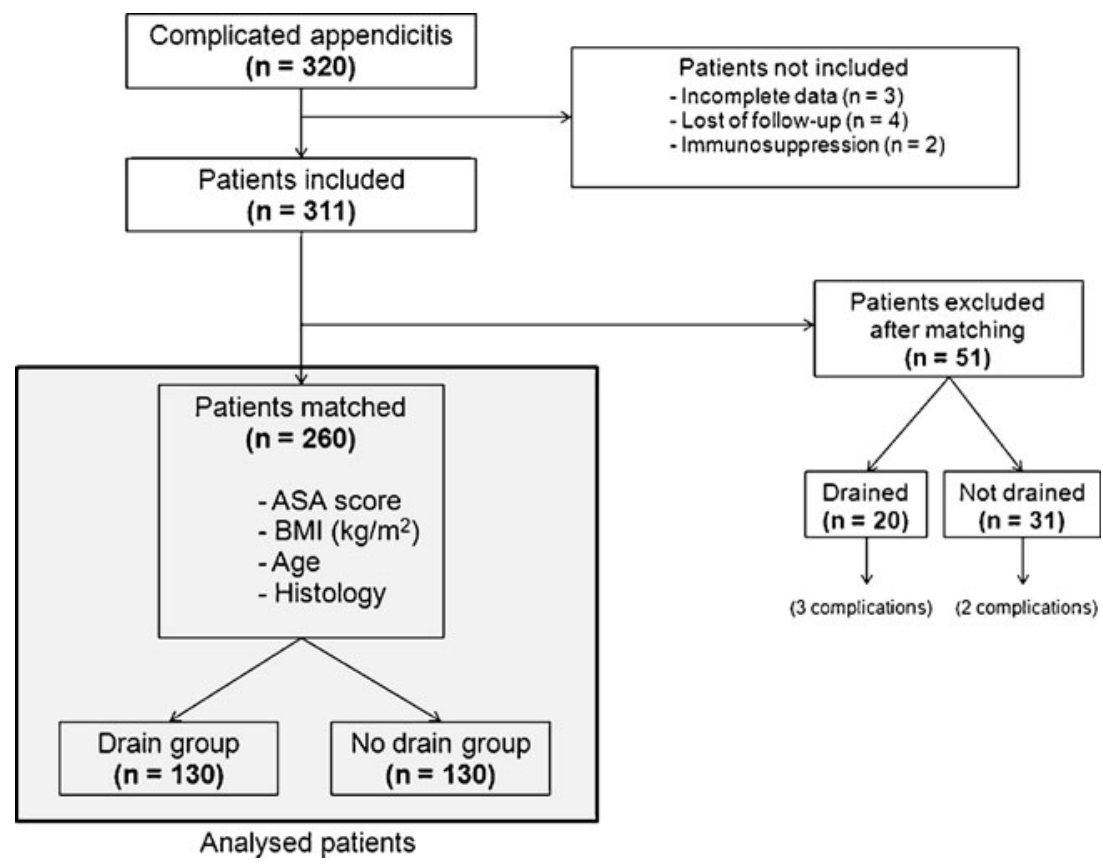

in case of allergy; first dose intravenous, then per oral). The pneumoperitoneum was always established by an open approach at the umbilicus. The base of the appendix was closed by either using endoloops (macroscopically normal tissue) or linear stapling devices (inflamed tissue), respectively. If drainage was used, it was placed near the resection site and exteriorized in the right iliac fossa, through one of the trocar site. The type of drain (open or closed system) was upon the individual surgeon's choice. An Endobag ${ }^{\circledR}$ was routinely used for the removal of the specimen.

Drains were removed $48 \mathrm{~h}$ after the intervention, if they drained less than $50 \mathrm{ml} /$ day of clear fluid. Otherwise, they were kept in place until this condition was satisfied.

Postoperative alimentation was identical in the two groups: patients had free fluids after recovery from anesthesia and free food at will from postoperative day 1 .

\section{Results}

Primary endpoint (surgical complications)

The mean follow-up time was 12 months (range 0.5240 months). All complications occurred within the first 30 post-operative days.

There was no patient with more than one complication.

We found a statistically significant lower overall complication rate in the no-drain group, compared to the drained group $(7.7 \%$ vs. $18.5 \%, p=0.01)$, mainly due to low-grade complications. A detailed analysis revealed that abdominal wall abscesses were significantly more frequent in the drain group (4 vs. $1, p<0.01$ ). All other types of complications were equally found in both groups, as shown in Fig. 2. As shown in Fig. 3, the analysis of the severity of complications showed that low-grade complications (types

Table 1 Patient characteristics

$B M I$ body mass index, $A S A$

American Society of

Anesthesiologists

${ }^{*} p>0.05$, Wilcoxon test

${ }^{* *} p>0.05$, McNemar test

\begin{tabular}{llll}
\hline & Drain group & No drain group & $p$ Value \\
\hline Number of patients & 130 & 130 & \\
Sex ratio m/f & $72: 58$ & $83: 67$ & \\
Median age (range) $(\mathrm{yrs})$ & $38(16-75)$ & $31(16-71)$ & n.s. \\
Median BMI (range) $\left(\mathrm{kg} / \mathrm{m}^{2}\right)$ & $24.2(17.2-43.4)$ & $24.5(16.7-40.1)$ & n.s.* \\
Median ASA score $(1 / 2 / 3 / 4)$ & $60 / 66 / 4 / 0$ & $55 / 71 / 4 / 0$ & n.s.** \\
Median leucocytes (range) $(\mathrm{G} / \mathrm{L})$ & $14.0(4-28.3)$ & $14.3(4.1-23.6)$ & n.s.* \\
Pathological findings & & & \\
$\quad$ Local peritonitis without perforation & 75 & 85 & n.s.** \\
Local peritonitis with perforation & 49 & 41 & n.s.** \\
Periappendicular abscess & 6 & 4 & n.s.** \\
\hline
\end{tabular}


Fig. 2 Details of surgical complications

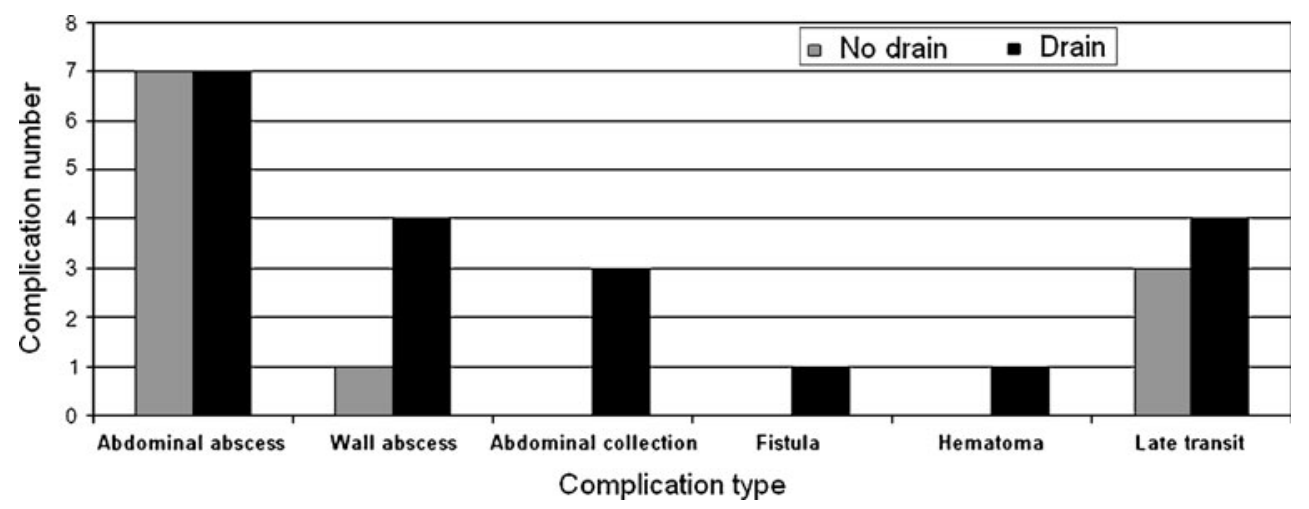

I and II) were significantly more frequent in the drained group (17 vs. 4, $p=0.003$ ), whereas no difference was observed for severe complications (types III-V).

Secondary endpoints

The mean transit recovery time was shorter in the no-drain group ( 2.5 vs. 3.5 days, $p=0.0068$ ), as well as the mean length of hospital stay (4.2 vs. 7.3 days, $p<0.001$ ).

Types of drains and timing of its removal

While $96 \%$ of all drains were removed after $48 \mathrm{~h}$, the remaining $4 \%$ stayed upon a mean time of 10 days (range 3-21 days). Passive drains were used in $74 \%$ of patients, whereas closed suction connected to a vacuum device drains have been used in the remaining $36 \%$ of patients. After univariate analysis, no statistically significant relation was observed between the type of drains and the amount of complications.

\section{Discussion}

There is increasing evidence in the literature that postoperative drainage of the abdominal cavity is not mandatory, and could, therefore, be abandoned without any increased risk for patient's safety. This current study assessed the role of routine abdominal drainage after laparoscopic appendectomy for complicated appendicitis in emergency settings.

Our progressive change of prophylactic drainage policy for laparoscopic appendectomy offered the opportunity to assess the role of such attitude. Despite a retrospective design, which limits the value of our results, we could establish a homogenous patient population between the groups, minimizing selection bias by matching for age, ASA, BMI, and histological status.

There are two different intentions to drain the abdominal cavity in the setting of emergency surgery [28]. First, there may be therapeutic reasons, e.g., providing an egress for intra-abdominal contamination or infections, or controlling a source of infection by creating a guided external fistula. Second, there may be prophylactic indications, e.g., preventing recurrent infection by evacuating residual fluid collections, controlling expected leakage from suture lines, and heralding complications such as bleeding or anastomotic leakage. Routine postoperative drainage in the setting of complicated appendicitis includes therapeutic and prophylactic aspects, i.e., evacuating residual periappendicular abscess and preventing recurrent intra-abdominal infection, respectively.

The first important result of this current study is the significantly increased overall complication rate in the patient group with routine drainage that is caused by
Fig. 3 Comparison of complications severity following Zurich's score

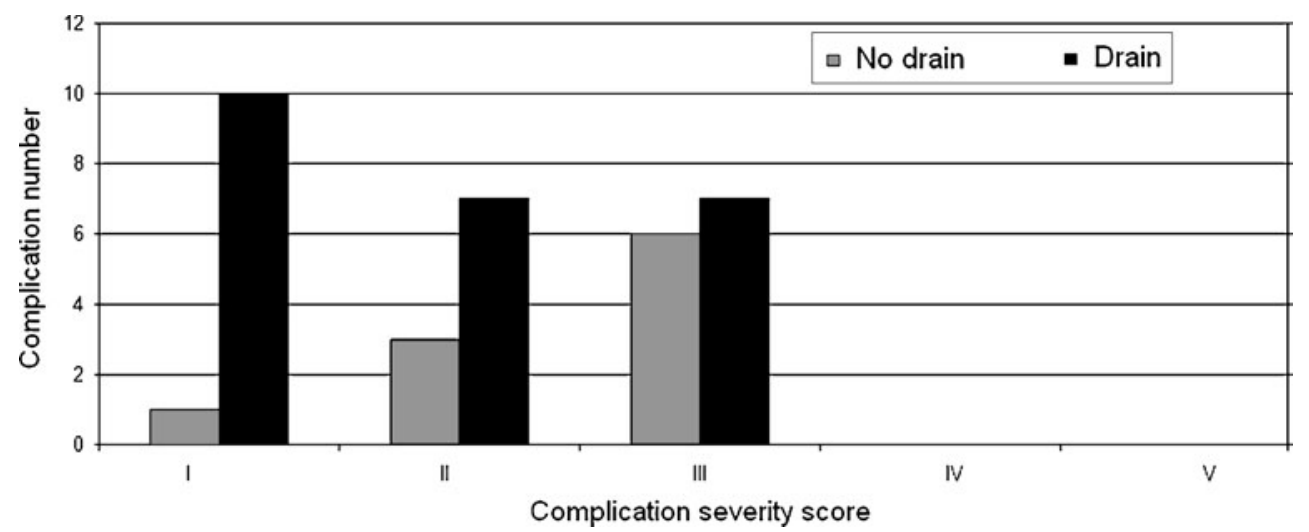


the high number of abdominal wall infections related to the drain exit site. The presence of a drain may facilitate contaminated liquids to flow along the drain into the subcutaneous tissue and causing wound infections. This finding corresponds well to the study of Pessaux et al. and the meta-analysis of Gurusamy et al. who also found increased wound infection rates after drainage of the abdominal cavity during laparoscopic interventions [21, 29]. Thus, the only proven advantage of the laparoscopic versus the open approach, i.e., the reduced wound infection rate, gambled away by routinely inserted drains [10].

The second relevant finding is the failure of routinely placed drains to decrease the rate of intra-abdominal infections. The drainage group has a similar amount of deep infections compared to the no drain group $(5.4 \%$ vs. 5.4\%). Experimental studies have shown that prophylactic placement of drains is unable to drain the whole abdominal cavity [28]. It can, therefore, be assumed that postoperative intra-abdominal abscess formation rather develops on missed fluid collections than on residual abscess cavities, which are rapidly filled by adjacent organs, e.g., the greater omentum. This observation is in favor for a meticulous surgery that removes the inflamed appendix as well as all infected fluid collections and abscess within the abdominal cavity. Postoperatively, the peritoneal defense mechanism will cure any residual infection without further external drainage [30].

We can only speculate why transit times in the drain group were prolonged. Direct contact between drains and the intestines may impair bowel activity. Furthermore, oral nutrition may be started with some delay using a more conservative postoperative regimen in drained patients considering them "as more sick," even if this was not the case in our study, as both groups had the same alimentation policy. Finally, wound infections of the abdominal wall may intensify bowel paralysis.

It is clinically obvious that complications and its treatment prolong the length of hospital stay. In addition, patients often remained hospitalized as long as drains had not yet been removed. Although this was not particularly investigated in this study, longer hospital stay will also increase cost.

\section{Conclusion}

Within the limits of a retrospective design, this study suggests that routine drainage of the abdominal cavity for complicated appendicitis may be associated with an increased wound infection rate, whereas intra-abdominal infections could not be prevented. Therefore, routine drainage of the peritoneal cavity may not longer be performed.
Conflicts of interest None.

\section{References}

1. Cueto J, Dallemagne B, Vázquez-Frias JA, Gomez S, Delgado F, Trullenque L, Fajardo R, Valencia S, Poggi L, Ballí J, Diaz J, González R, Mansur JH, Franklin ME (2006) Morbidity of laparoscopic surgery for complicated appendicitis: an international study. Surg Endosc 20(5):717-720

2. Ming PC, Yan TY, Tat LH (2009) Risk factors of postoperative infections in adults with complicated appendicitis. Surg Laparosc Endosc Percutan Tech 19(3):244-248

3. Garg CP, Vaidya BB, Chengalath MM (2009) Efficacy of laparoscopy in complicated appendicitis. Int J Surg 7(3):250-252

4. Faiz O, Clark J, Brown T, Bottle A, Antoniou A, Farrands P, Darzi A, Aylin P (2008) Traditional and laparoscopic appendectomy in adults: outcomes in English NHS hospitals between 1996 and 2006. Ann Surg 248(5):800-806

5. Van Hove C, Hardiman K, Diggs B, Deveney C, Sheppard B (2008) Demographic and socioeconomic trends in the use of laparoscopic appendectomy from 1997 to 2003. Am J Surg 195 (5):580-583, discussion 583-584

6. Paterson HM, Qadan M, de Luca SM, Nixon SJ, Paterson-Brown S (2008) Changing trends in surgery for acute appendicitis. Br J Surg 95(3):363-368

7. Yau KK, Siu WT, Tang CN, Yang GP, Li MK (2007) Laparoscopic versus open appendectomy for complicated appendicitis. J Am Coll Surg 205(1):60-65

8. Moberg AC, Berndsen F, Palmquist I, Petersson U, Resch T, Montgomery A (2005) Randomized clinical trial of laparoscopic versus open appendicectomy for confirmed appendicitis. Br J Surg 92(3):298-304

9. Katkhouda N, Mason RJ, Towfigh S, Gevorgyan A, Essani R (2005) Laparoscopic versus open appendectomy: a prospective randomized double-blind study. Ann Surg 242(3):439-448, discussion $448-450$

10. Aziz O, Athanasiou T, Tekkis PP, Purkayastha S, Haddow J, Malinovski V, Paraskeva P, Darzi A (2006) Laparoscopic versus open appendectomy in children: a meta-analysis. Ann Surg 243 (1): $17-27$

11. Lin HF, Wu JM, Tseng LM, Chen KH, Huang SH, Lai IR (2006) Laparoscopic versus open appendectomy for perforated appendicitis. J Gastrointest Surg 10(6):906-910

12. Fukami Y, Hasegawa H, Sakamoto E, Komatsu S, Hiromatsu T (2007) Value of laparoscopic appendectomy in perforated appendicitis. World J Surg 31(1):93-97

13. Harrell AG, Lincourt AE, Novitsky YW, Rosen MJ, Kuwada TS, Kercher KW, Sing RF, Heniford BT (2006) Advantages of laparoscopic appendectomy in the elderly. Am Surg 72(6):474480

14. Sauerland S, Lefering R, Neugebauer EA (2002) Laparoscopic versus open surgery for suspected appendicitis. Cochrane Database Syst Rev 1:CD001546

15. Kehagias I, Karamanakos SN, Panagiotopoulos S, Panagopoulos K, Kalfarentzos F (2008) Laparoscopic versus open appendectomy: which way to go? World J Gastroenterol 14(31):4909-4914

16. Katsuno G, Nagakari K, Yoshikawa S, Sugiyama K, Fukunaga M (2009) Laparoscopic appendectomy for complicated appendicitis: a comparison with open appendectomy. World J Surg 33(2):208214

17. Tander B, Pektas O, Bulut M (2003) The utility of peritoneal drains in children with uncomplicated perforated appendicitis. Pediatr Surg Int 19:548-550 
18. Stone HH, Hooper CA, Millikan WJ (1978) Abdominal drainage following appendectomy and cholecystectomy. Ann Surg 187:606-612

19. Magarey CJ, Chant ABD, Rickford CRK (1971) Peritoneal drainage and systemic antibiotics after appendectomy. Lancet 2:179-182

20. Toki A, Ogura K, Sato Y (1995) Peritoneal lavage versus drainage for perforated appendicitis in children. Surg Today 25 (3):207-210

21. Pessaux P, Msika S, Flamant Y (2003) Risk factors for postoperative infectious complications in noncolorectal abdominal surgery. Arch Surg 138:314-324

22. Kokoska ER, Silen ML, Webwe TR (1998) Perforated appendicitis in children: risk factors for development of complications. Surgery 124(4):619-626

23. Alloo J, Gerstle T, Ein SH (2004) Appendicitis in children less than 3 years of age: a 28-year review. Pediatr Surg Int 19:777779

24. Neilson IR, Laberge JM, Nguyen LT, Moir C, Doody D, Sonnino RE, Youssef S, Guttman FM (1990) Appendicitis in children: current therapeutic recommendations. J Pediatr Surg 25(11):11131116

25. Narci A, Karaman I, Karaman A, Erdoğan D, Cavuşoğlu YH, Aslan MK, Cakmak O (2007) Is peritoneal drainage necessary in childhood perforated appendicitis? - a comparative study. J Pediatr Surg 42(11):1864-1868

26. Petrowsky H, Demartines N, Clavien PA (2004) Evidence-based values of prophylactic drainage in gastrointestinal surgery. Ann Surg 240:1074-1085

27. Dindo D, Demartines N, Clavien PA (2004) Classification of surgical complications: a new proposal with evaluation in a cohort of 6336 patients and results of a survey. Ann Surg 240(2):205-213

28. Schein M (2008) To drain or not to drain? The role of drainage in the contaminated and infected abdomen: an international and personal perspective. World J Surg 32(2):312-321

29. Gurusamy KS, Samraj K, Mullerat P, Davidson BR (2007) Routine abdominal drainage for uncomplicated laparoscopic cholecystectomy. Cochrane Database Syst Rev 17(4):CD006004

30. Wittmann DH, Schein M, Condon RE (1996) Management of secondary peritonitis. Ann Surg 224(1):10-18 